\title{
CALL FOR PAPERS: RESEARCH ON STATISTICAL LITERACY
}

The Statistics Education Research Journal (SERJ), a journal of the International Association for Statistical Education (IASE), announces a special issue on the topic of Research on Statistical Literacy, currently planned for May 2017.

Deadlines: Expressions of intent by February 28, 2015, full papers by December 1, 2015.

The Guest Editors for this special edition will be Jim Ridgway (jim.ridgway@durham.ac.uk) and James Nicholson (j.r.nicholson@durham.ac.uk), with current SERJ co-editor Maxine Pfannkuch (m.pfannkuch@auckland.ac.nz).

\section{BACKGROUND}

SERJ has had a number of special editions in its previous volumes: research on reasoning about variability (vol. 3, no. 2, 2004); reasoning about distribution (vol. 5, no. 2, 2006); informal inference (vol. 7, no. 2, 2008); qualitative approaches in statistics education research (vol. 9, no. 2, 2010); attitudes towards statistics (vol. 11, no. 2, 2012); and a global view of statistics education research (vol. 13, no. 2, 2014).

Statistical literacy is not a well-defined construct. It is widely accepted to include a capacity to engage in informed debate about issues in which data-based arguments are put forward, but the extent to which different components of the arguments (e.g., the provenance of the data, the suitability of sampling methods, the suitability and accuracy of the analysis, the validity of the conclusions posited) are essential facets of statistical literacy, enjoys much less consensus.

\section{POSSIBLE TOPICS}

Examples of topics that are relevant to this special issue on Research on Statistical Literacy include, but are not limited to, reporting on research about literacies associated with:

a. Understanding data presented in the media - both in news and in advertising.

b. Critiquing uses of data in public policy, such as the use of performance indicators in public services.

c. Analyzing argumentation underpinned by data.

d. The data revolution.

e. Data visualization.

f. Decision making, including estimating utilities and risks.

Contributions are also welcomed on reporting on research about approaches to enhancing statistical literacy, including:

g. Innovative teaching approaches.

h. Cooperation between data producers (e.g., National Statistics Offices) and others.

i. Uses of social media.

Statistics Education Research Journal, 13(2), 13-14, http://iase-web.org/Publications.php?p=SERJ C International Association for Statistical Education (IASE/ISI), November, 2014 


\section{SUBMISSION GUIDELINES}

Manuscripts for this special issue will be limited to a maximum of 7500 words of body text and authors are encouraged to aim for 4000-6000 words of body text (not counting abstract, tables and graphs, references, appendices). Note particularly that manuscripts can be written in Spanish, French or English; those in Spanish or French will be published with an English summary of around 1000 words (see the papers by Mayén et al. in vol. 8, no. 2, and by BihanPoudec in vol. 9, no. 2).

Manuscripts should be submitted in accordance with SERJ's standard Author Guidelines and using the Template file found on the Journal website: http://iaseweb.org/Publications.php?p=SERJ. The general author guidelines for SERJ can be found at http://iase-web.org/documents/SERJdocs/authorguide.pdf.

\section{DEADLINES AND CONTACT INFORMATION}

Interested authors should send a letter of intent by February 28, 2015, but preferably earlier, consisting of a 150-250 word abstract describing key aspects of the paper. This letter should be sent by e-mail to Jim Ridgway (jim.ridgway@durham.ac.uk), one of the SERJ guest editors for this special issue. Authors will be sent an acknowledgement of their letter, and can expect to receive an initial response from the editorial team within three weeks. A fuller response with decisions about proceeding to submit a full paper will be sent by March 31, 2015 to all who submit letters of intent. Potential authors with informal queries regarding the suitability of a planned paper are also encouraged to contact any member of the team.

Full manuscripts must be submitted by December 1, 2015 at the latest, to Jim Ridgway in accordance with the submission guidelines listed earlier. Again, authors will be sent an acknowledgement of the manuscript's receipt.

Decisions about the suitability of proposed papers and the allocation of accepted papers to the special issue (or alternatively to a regular $S E R J$ issue) will be made jointly by the guest editors and the SERJ editors. 